\title{
Performance of a corona ion source for measurement of sulfuric acid by chemical ionization mass spectrometry
}

\author{
A. Kürten, L. Rondo, S. Ehrhart, and J. Curtius \\ Institute for Atmospheric and Environmental Sciences, Johann Wolfgang Goethe University Frankfurt am Main, \\ 60438 Frankfurt am Main, Germany
}

Received: 10 November 2010 - Published in Atmos. Meas. Tech. Discuss.: 19 November 2010

Revised: 11 February 2011 - Accepted: 25 February 2011 - Published: 3 March 2011

\begin{abstract}
The performance of an ion source based on corona discharge has been studied. This source is used for the detection of gaseous sulfuric acid by chemical ionization mass spectrometry (CIMS) through the reaction of $\mathrm{NO}_{3}^{-}$ions with $\mathrm{H}_{2} \mathrm{SO}_{4}$. The ion source is operated under atmospheric pressure and its design is similar to the one of a radioactive (americium-241) ion source which has been used previously. The results show that the detection limit for the corona ion source is sufficiently good for most applications. For an integration time of $1 \mathrm{~min}$ it is $\sim 6 \times 10^{4}$ molecule $\mathrm{cm}^{-3}$ of $\mathrm{H}_{2} \mathrm{SO}_{4}$. In addition, only a small cross-sensitivity to $\mathrm{SO}_{2}$ has been observed for concentrations as high as $1 \mathrm{ppmv}$ in the sample gas. This low sensitivity to $\mathrm{SO}_{2}$ is achieved even without the addition of an $\mathrm{OH}$ scavenger. When comparing the new corona ion source with the americium ion source for the same provided $\mathrm{H}_{2} \mathrm{SO}_{4}$ concentration, both ion sources yield almost identical values. These features make the corona ion source investigated here favorable over the more commonly used radioactive ion sources for most applications where $\mathrm{H}_{2} \mathrm{SO}_{4}$ is measured by CIMS.
\end{abstract}

\section{Introduction}

The measurement of gaseous sulfuric acid is important since $\mathrm{H}_{2} \mathrm{SO}_{4}$ is one of the key compounds responsible for atmospheric new particle formation (Eisele and Tanner, 1993; Weber et al., 1995, 1997, 1999; Curtius, 2006; Kulmala and Kerminen, 2008). The nucleation of particles has been observed in many places around the world on ground-based measurement sites as well as in the free troposphere (Kulmala et al., 2004). In most cases the formation rate of new particles cor-

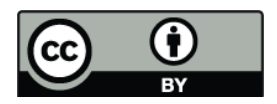

Correspondence to: A. Kürten

(kuerten@iau.uni-frankfurt.de) relates with the concentration of sulfuric acid (Yu and Turco, 2001; Fiedler et al., 2005; Kuang et al., 2008). The concentration of $\mathrm{H}_{2} \mathrm{SO}_{4}$ during atmospheric nucleation events is usually between $10^{6}$ and $10^{7}$ molecule $\mathrm{cm}^{-3}$ (Sipilä et al., 2010), i.e. in the sub-ppt range under standard conditions. Therefore, the precise and accurate measurement of sulfuric acid is essential for studying new particle formation under atmospheric conditions as well as during chamber experiments.

For the real-time measurement of sulfuric acid, chemical ionization mass spectrometry (CIMS) is generally deployed. CIMS is a very sensitive and selective method and detection limits around $10^{5}$ molecule $\mathrm{cm}^{-3}$ of $\mathrm{H}_{2} \mathrm{SO}_{4}$ and one minute integration time can be reached (Eisele and Tanner, 1993; Young et al., 2008). While most instruments initiate the production of the $\mathrm{NO}_{3}^{-}$primary ions - which are used for $\mathrm{H}_{2} \mathrm{SO}_{4}$-CIMS - through the decay of a radioactive substance, these ions can also be generated by a corona discharge. Radioactive sources are used (usually alpha emitters like polonium-210 or americium-241) because they are known to be more stable over time and produce cleaner mass spectra, i.e. create lower background concentrations and less interference with other substances like $\mathrm{SO}_{2}$. However, with respect to health risk, cost and meeting safety regulations for shipment, storage and operation, corona ion sources have a clear advantage over their radioactive counterparts.

Corona ion sources for CIMS instruments have been described and used by several groups for the measurement of $\mathrm{OH}$ and peroxy radicals (Kukui et al., 2008), other atmospheric trace gases like $\mathrm{SO}_{2}$, acetonitrile and acetone (Jost et al., 2003) as well as $\mathrm{HNO}_{3}$ (Furutani and Akimoto, 2002; Zheng et al., 2008). Using drift-chemical ionization mass spectrometry, corona ion sources have also been deployed for the detection of $\mathrm{N}_{2} \mathrm{O}_{5}$ and isoprene (Zheng et al., 2008; Fortner et al., 2004). Some of the corona ion source-based measurements show a higher complexity as compared to the use

Published by Copernicus Publications on behalf of the European Geosciences Union. 


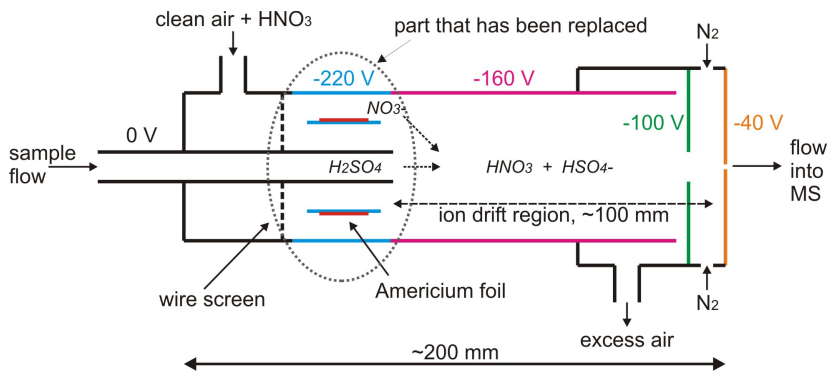

Fig. 1. Schematical drawing of the ion source and the inlet system of the instrument used for the $\mathrm{H}_{2} \mathrm{SO}_{4}$ measurements. The colors represent different voltages applied to the different sections of the inlet and ion source region. Note that the voltage applied to the americium foil is $-220 \mathrm{~V}$ as well but has been assigned a different color for clarity.

of radioactive ion sources (Kukui et al., 2008) while they suffer at the same time from higher detection limits due to radicals produced by the corona discharge (Kukui et al., 2008; Jost et al., 2003). The findings presented here, however, do not support these observations, something which might be related to the special design of the ion source region and the ion drift tube of the instrument being used in this study.

Here, we describe in detail the set-up of a corona-type ion source and report on its performance when used with a chemical ionization mass spectrometer from THS Instruments (THS Instruments LLC, USA). The results obtained with this ion source are compared to the ones from an americium ion source, a device generally used for this type of CIMS measurement. It is demonstrated that the corona ion source works, it is stable and reliable. Furthermore, it shows a negligible cross-sensitivity to $\mathrm{SO}_{2}$ for sulfuric acid measurements when using a sample flow rate of $7.5 \mathrm{slm}$ (standard liters per minute) and a sheath gas flow rate of $\sim 22 \mathrm{slm}$, respectively. Most importantly, the corona ion source yields almost identical quantitative results as an americium ion source for the same instrument.

\section{Instrumental description}

The corona ion source has been developed for a chemical ionization mass spectrometer from THS Instruments (THS Instruments LLC, USA) for the detection of sulfuric acid. The measurement relies on the reaction between $\mathrm{NO}_{3}^{-}$primary ions generated in the ion source and sulfuric acid in the sample gas (see Eisele and Tanner, 1993; Berresheim et al., 2000). Originally, the instrument was equipped with an americium containing thin gold-plated foil (NRD LLC, USA) for providing the primary ions. A schematical drawing of this ion source is shown in Fig. 1. This figure, showing the old set-up, is used to illustrate the working principle of the instrument while the new corona ion source will be introduced and explained in detail further below.

\subsection{CIMS and americium ion source}

The sample gas containing the sulfuric acid is pulled into the ion drift region through a stainless steel tube with an outer diameter of $12.7 \mathrm{~mm}$. It is then exposed to $\mathrm{NO}_{3}^{-}\left(\mathrm{HNO}_{3}\right)_{x}$ with $x=0-2$ primary ions which can react with $\mathrm{H}_{2} \mathrm{SO}_{4}$ to form $\mathrm{HSO}_{4}^{-}\left(\mathrm{HNO}_{3}\right)_{x}$ ions (Eisele and Tanner, 1993; Viggiano et al., 1997). The primary ions in the old set-up originate from the interaction of alpha particles (from the radioactive decay of americium-241) with the sheath gas. This sheath gas consists of room air cleaned by an activated charcoal as well as by a HEPA filter and has a total flow rate of approximately 22 standard liters per minute (slm). A small amount of $\mathrm{HNO}_{3}\left(\sim 0.005 \mathrm{slm}\right.$ of $\mathrm{N}_{2}$ saturated with $\mathrm{HNO}_{3}$ at room temperature) is added to the sheath gas which leads to the generation of $\mathrm{NO}_{3}^{-}\left(\mathrm{HNO}_{3}\right)_{x}$ primary ions through a series of ion/molecule interactions. In order to shield the sample gas from radicals produced in the region around the americium foil there is an annular space between the $12.7 \mathrm{~mm}$ tube and the cylinder which holds the americium foil. It is thought that radicals such as $\mathrm{OH}$ remain largely in the sheath flow while ions are drawn into the sample flow. Therefore, $\mathrm{OH}$ should not react with $\mathrm{SO}_{2}$ to produce spurious amounts of $\mathrm{H}_{2} \mathrm{SO}_{4}$. The generated $\mathrm{NO}_{3}^{-}\left(\mathrm{HNO}_{3}\right)_{x}$ ions, however, are mixed with the sample gas. This is achieved by applying electrostatic voltages to different sections of the ion source, the sample tube and the ion drift tube, respectively, thereby focusing the primary ions towards the centerline of the ion/sample gas interaction region. While the sample and sheath gas mixture containing the neutral molecules is pumped away, the ions are accelerated towards the pinhole plate which separates the vacuum region of the mass spectrometer from the ion drift region. A small flow of dry nitrogen is used to evaporate excess water from the ions. Behind the pinhole plate the ions are guided through an octopole where most of them are declustered by removing excess $\mathrm{HNO}_{3}$ and $\mathrm{H}_{2} \mathrm{O}$ molecules. The primary ions and the analyte ions are then detected by a quadrupole mass spectrometer and a channeltron at $m / z 62\left(\mathrm{NO}_{3}^{-}\right)$or $\mathrm{m} / \mathrm{z} 64\left(\mathrm{NO}_{2}^{18} \mathrm{O}^{-}\right)$and $\mathrm{m} / \mathrm{z}$ $97\left(\mathrm{HSO}_{4}^{-}\right)$, respectively. The ratio of the measured count rates, together with the reaction time and the reaction rate yields the concentration of sulfuric acid in the sample gas (Berresheim et al., 2000).

\subsection{Corona ion source}

The same measurement principle has been used for the setup with the corona ion source and only a few adjustments were made to the outer stainless steel cylinder which houses the ion source (the part where $-220 \mathrm{~V}$ are applied to, see Fig. 1). The overall length of the outer cylinder has been increased from 40 to $50 \mathrm{~mm}$ in order to eliminate any contributions to the electric field in the ion drift region from the electric field of the corona needle. If the corona needle is too close to the edge where the inner cylinder terminates then 


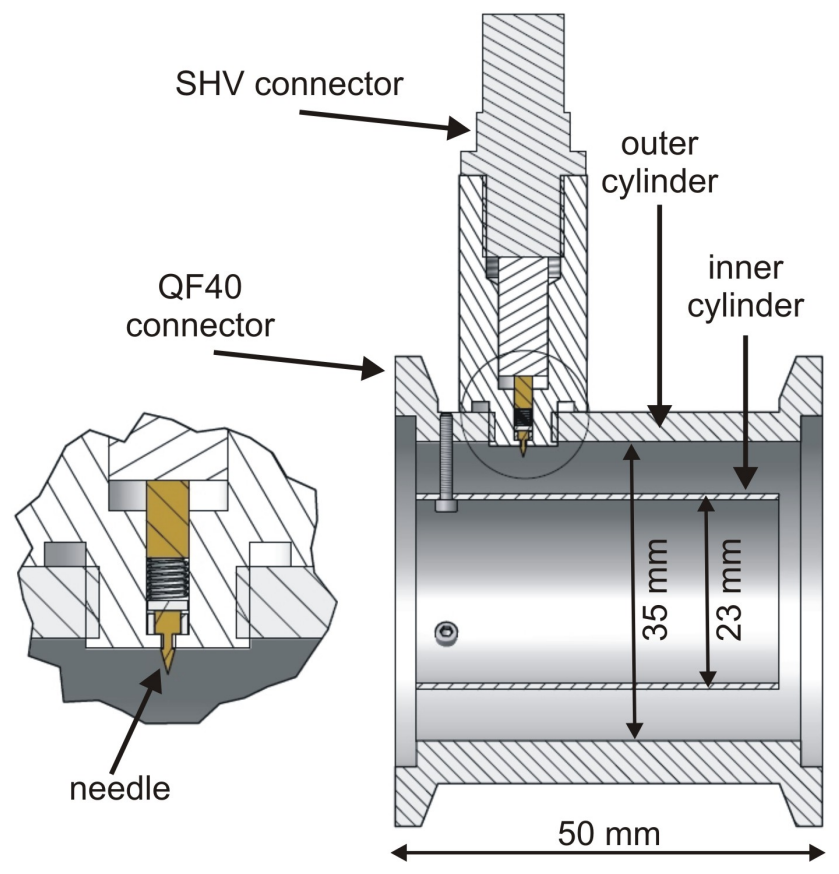

Fig. 2. Technical drawing of the new corona ion source set-up. The section on the left shows the magnified corona needle (in gold) and the compression spring which establishes the electrical contact to the SHV feedthrough. Direction of flows is from left to right.

the high voltage applied to the needle can distort the electric field and destroy its cylindrical symmetry. Therefore, the needle has been moved slightly upstream in order to shield the ion/sample gas mixing zone from the electric field the high voltage creates (see Fig. 2). In order to create the corona discharge a needle from acupuncture supply (Moxom SP-X Gold, Moxom Acupuncture GmbH, Germany) was chosen. These needles have the advantage that they are industrially machined with high precision and therefore differ very little from each other. No adjustment needs to be made to a needle; each one can be used as is. Another advantage is that they are gold-plated and are therefore not dissolved by the $\mathrm{HNO}_{3}$ in the sheath gas. Additionally, a comparison of different corona needle materials has shown that needles made of gold show a preferable combination of both durability and relatively low production of $\mathrm{NO}_{\mathrm{x}}$ and $\mathrm{O}_{3}$ (Asbach et al., 2005). The type of needles used here has a cylindrical shape at its blunt end with an outer diameter of $\sim 1.3 \mathrm{~mm}$. Although this size is still rather small it allows handling and aligning the needle rather easily compared to other thinner needles or wires. An adapter piece made of PEEK (polyether ether ketone) was machined which allows installing and exchanging a needle easily. Due to these advantages we haven't observed any change in the performance of the ion source after a needle has been exchanged meaning that results are reproducible within normal variations of the ion count rate. The overall length of the needle from its sharp tip to the cylindrical end is $\sim 3.1 \mathrm{~mm}$. The needle is held by a little ring made of stainless steel which centers it inside a cylindrical bore of the PEEK part. This part has a tiny through-hole which allows the tip of the needle to penetrate but not its cylindrical part. The diameter of the hole is just big enough such that the needle can be pressed through the hole. It is then held in place because it is slightly cylindrically barbed. The other end of the PEEK part has an internal thread to fit a standard o-ring-sealed high voltage feedthrough (SHV type). The electrical contact between the SHV connector and the needle is established by means of a small stainless steel compression spring (Century Spring Corp., USA) and a stainless steel disc. The PEEK part has also an outer thread and can be attached and sealed to the stainless steel ion source housing with an o-ring.

Instead of aligning the needle tip in the center of the annular space between the inner and the outer cylinder, the needle was moved slightly further towards the outside wall. The idea behind this is that radicals produced close to the needle surface are further away from the centerline of the ion source and are therefore less likely to interact with the sample gas. Instead of using just one corona needle a set-up with four corona needles, aligned $90^{\circ}$ apart from each other (when viewed perpendicularly to the gas flow direction), was also tried-out. However, this set-up did not improve the overall functionality. We think that space charge effects might suffice distributing the ions homogenously even when only one point source for the ion generation is used (see also discussion in Sect. 3.1).

The electronics driving the corona needle voltage is relatively simple. A negative high voltage supply (model 4100 N, EMCO High Voltage Corporation, USA) is used which is set to a static voltage (adjusted between $-5 \mathrm{kV}$ and $-7.5 \mathrm{kV})$. The high voltage is connected in series with a resistor (500 MOhm) and the corona needle. The corona onset voltage is around $-3 \mathrm{kV}$ (with respect to the $-220 \mathrm{~V}$ applied to the ion source housing). Therefore, the resistor limits the current between $\sim 4 \mu \mathrm{A}$ and $9 \mu \mathrm{A}$. Having the resistor in series with the corona needle both limits and stabilizes the corona current since random changes in the corona onset voltage (e.g. due to changes in the gas humidity) then translate only into small changes of the corona current. Therefore, the ion current is quite stable even without actively controlling for a defined corona emission current (e.g. with a PID controller).

\section{Results and discussion}

Desired features for a $\mathrm{H}_{2} \mathrm{SO}_{4}-\mathrm{CIMS}$ ion source are a simple set-up and low maintenance, low background signal, especially no cross-sensitivity to $\mathrm{SO}_{2}$, long-term stability and most importantly the capability of quantitative measurements. As mentioned in the previous section the corona ion source can be set-up easily and replacement needles can be purchased inexpensively and can be exchanged quickly. 


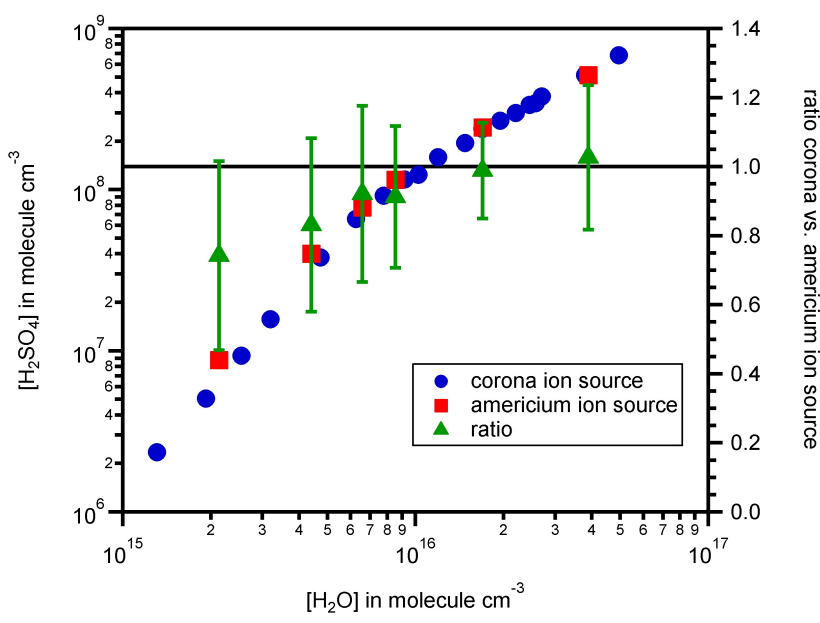

Fig. 3. Measured $\mathrm{H}_{2} \mathrm{SO}_{4}$ concentrations when operating the CIMS instrument with an americium and with a corona ion source, respectively. Different $\mathrm{H}_{2} \mathrm{SO}_{4}$ concentrations were adjusted by a calibration system. These are a function of $\left[\mathrm{H}_{2} \mathrm{O}\right]$ shown on the $\mathrm{x}$-axis. Error bars for the $\mathrm{H}_{2} \mathrm{SO}_{4}$ values have been neglected for clarity. The main error for the ratios between the values for the corona and the americium ion source comes from the uncertainty in the temperature measurement (which is assumed to be $\pm 1^{\circ} \mathrm{C}$ ). This error in temperature affects the conversion from relative humidity into concentration of $\mathrm{H}_{2} \mathrm{O}$ strongly due to the dependence of the water vapor saturation pressure on temperature.

\subsection{Comparison between corona and americium ion source for given $\mathrm{H}_{2} \mathrm{SO}_{4}$ concentrations}

The measurement of different amounts of $\mathrm{H}_{2} \mathrm{SO}_{4}$ has been tested both for the americium ion source and the corona ion source with set-ups according to Figs. 1 and 2, respectively. The $\mathrm{H}_{2} \mathrm{SO}_{4}$ has been generated by an external calibration source which provides adjustable and stable concentrations of $\mathrm{H}_{2} \mathrm{SO}_{4}$. The detailed set-up of this calibration source will be described in a forthcoming paper and is therefore only briefly explained here. A gas mixture of $\mathrm{N}_{2}, \mathrm{O}_{2}, \mathrm{SO}_{2}$ and $\mathrm{H}_{2} \mathrm{O}$ is illuminated by $185 \mathrm{~nm}$ UV light from a mercury lamp which photolyzes water vapor and leads to the formation of $\mathrm{OH}$. This $\mathrm{OH}$ reacts further with $\mathrm{SO}_{2}, \mathrm{O}_{2}$ and $\mathrm{H}_{2} \mathrm{O}$ to form sulfuric acid (see also Young et al., 2008). Varying the amount of $\mathrm{H}_{2} \mathrm{O}$ yields different concentrations of $\mathrm{H}_{2} \mathrm{SO}_{4}$. The calibration of the CIMS has been performed once in June 2010 when the americium ion source was still in use. After switching to the corona ion source, the calibration has been repeated with the same calibration source under similar conditions. As can be seen from Fig. 3 the instrument shows almost identical responses to a given $\mathrm{H}_{2} \mathrm{SO}_{4}$ concentration within the uncertainty range, no matter whether the corona ion source or the americium ion source was used. While the points for the two highest $\left[\mathrm{H}_{2} \mathrm{O}\right]$ are perfectly corresponding to a $1: 1$ ratio, the points for the lower $\left[\mathrm{H}_{2} \mathrm{O}\right]$ seem to move progressively further away from this ratio. For a $\left[\mathrm{H}_{2} \mathrm{SO}_{4}\right]$ of $\sim 7 \times 10^{6}$ molecule $\mathrm{cm}^{-3}$ the ratio reaches a value of 0.75 . However, we don't think this behavior is caused by any of the two different ion sources but rather reflects a feature of the calibration system in its current realization. The accuracy for adjusting the humidities becomes lower for dryer conditions and therefore the ratio of the $\left[\mathrm{H}_{2} \mathrm{SO}_{4}\right]$ measured by the two sources reflects this uncertainty. As shown in section 3.3 the corona source shows only a negligible cross-sensitivity to $\mathrm{SO}_{2}$ in the sample flow (from the reaction with $\mathrm{OH}$ produced by the discharge). Therefore, this contribution is quite small and if it was responsible for the observed deviation, the ratio should become larger than 1 because additional $\mathrm{H}_{2} \mathrm{SO}_{4}$ would be produced by the corona ion source. Since this is not the case, the cross-sensitivity to $\mathrm{SO}_{2}$ is unlikely responsible for the falloff in the ratio. Together, with the very good agreement for the higher concentrations, where the $\left[\mathrm{H}_{2} \mathrm{O}\right]$ could be adjusted much more accurately, the slight systematic discrepancy does not seem to be caused by any difference between the two ion sources. Especially when taking into account that the points shown in Fig. 3 are all corresponding to a ratio of 1 within the range of errors.

The observation that the correspondence between the corona and the americium ion source is nearly perfect is not necessarily expected given the fact that the ions from the corona needle are generated only by a point source whereas for the americium source they are produced over a complete circular cross section (neglecting the small gap between the edges of the americium foil when it is wrapped around the inner cylinder). However, our findings might suggest that space charge distributes the ions homogenously in the ion drift region. Another, maybe more likely explanation is that even when the primary ions are not homogenously distributed over the sample gas volume, only $\mathrm{NO}_{3}^{-}$ions which have been mixed with the sulfuric acid in the sample gas enter the vacuum. Therefore, the ion count rates for $\mathrm{HSO}_{4}^{-}$and $\mathrm{NO}_{3}^{-}$are always at a defined ratio for a given $\mathrm{H}_{2} \mathrm{SO}_{4}$ concentration and no $\mathrm{NO}_{3}^{-}$ions that were not exposed to sulfuric acid in the sample gas are counted. This behavior for the ion collection can be explained by the special design of the interface between the ion drift region and the pinhole plate through which the ions enter the vacuum of the mass spectrometer. In front of the pinhole an electrostatic lens (applied voltage of $-100 \mathrm{~V}$, see Fig. 1) with an internal diameter that is equal to the one of the sampling tube allows only ions to pass which are close to the centerline. Therefore, primary ions close to the outside wall of the ion drift tube are not detected and do not bias the ratio between analyte and reagent ions.

\subsection{Signal stability}

Figure 4 shows a time series of the signal at $\mathrm{m} / \mathrm{z} 64$ over a period of more than two hours. $\mathrm{NO}_{2}^{18} \mathrm{O}^{-}(\mathrm{m} / \mathrm{z}, 64)$ is used to determine the primary ion count rate because the signal at $m / z 62\left(\mathrm{NO}_{3}^{-}\right)$can saturate the channeltron detector. The data in the figure shows raw data with a time resolution of 


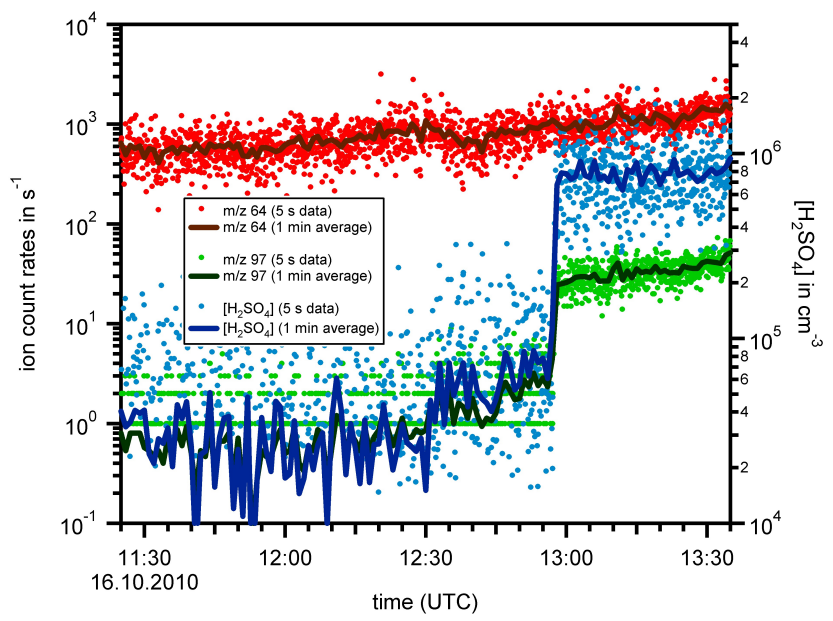

Fig. 4. Time series of the primary ion signal $\mathrm{NO}_{2}^{18} \mathrm{O}^{-}(m / z 64)$, the $\mathrm{HSO}_{4}^{-}$ion $(\mathrm{m} / z, 97)$ and the derived $\mathrm{H}_{2} \mathrm{SO}_{4}$ concentrations from the signals. $\mathrm{SO}_{2}$ at 1 ppmv was introduced into the sample gas at $12: 30 ; \mathrm{H}_{2} \mathrm{SO}_{4}$ was generated around 12:57 with a calibration setup external to the CIMS instrument. Please note that the data for $\mathrm{m} / \mathrm{z}, 97$ and $\left[\mathrm{H}_{2} \mathrm{SO}_{4}\right]$ includes many points showing values of zero, which are not visible on the logarithmic scale used here.

$\sim 5$ seconds as well as values averaged over 1 minute. Until 12:57 the background of $\mathrm{H}_{2} \mathrm{SO}_{4}$ was measured. Then a stable concentration of $\mathrm{H}_{2} \mathrm{SO}_{4}$ was produced in the calibration set-up. The signal of the primary ion shows some fluctuations and a small drift can be identified with a slightly increasing ion count rate over time. These changes were not observed as strongly with the americium ion source and the higher "noise" of the corona ion source might be caused by changes in the corona onset voltage due to temperature changes or slight changes in the sheath gas composition (humidity). However, these changes are rather small and slow. In addition, since $\left[\mathrm{H}_{2} \mathrm{SO}_{4}\right]$ is proportional to the ratio of the count rates at $m / z 97$ and $m / z 64$ these drifts do not show up in the $\mathrm{H}_{2} \mathrm{SO}_{4}$ signal. Over longer time scales of up to weeks the count rate of the primary ion signal stays within $\pm 50 \%$. This means that the same corona needle can be used for rather long times and that no observable limitation on the detection limits are occurring.

\subsection{Cross-sensitivity to $\mathrm{SO}_{2}$ and detection limit}

The dependence of the $\mathrm{H}_{2} \mathrm{SO}_{4}$ measurement on the $\mathrm{SO}_{2}$ concentration is also shown in Fig. 4. At 12:30 a concentration of 1 ppmv of $\mathrm{SO}_{2}$ was introduced into the sample gas while no $\mathrm{SO}_{2}$ had been actively introduced before. The average $\mathrm{H}_{2} \mathrm{SO}_{4}$ concentration increases from $2.9 \times 10^{4}$ to $\sim 6.1 \times 10^{4} \mathrm{~cm}^{-3}$ due to the higher $\mathrm{SO}_{2}$ concentration. When taking into account the point to point fluctuations for the signals, detection limits (based on the averaged one minute values plus three times their standard deviation) of $6.4 \times 10^{4} \mathrm{~cm}^{-3}$ and $1.1 \times 10^{5} \mathrm{~cm}^{-3}$ are obtained for the peri- ods without and with the addition of $\mathrm{SO}_{2}$, respectively. Even the higher value is still better than what has been reported from another group for a similar CIMS with a polonium ion source (Young et al., 2008).

The concentration of sulfur dioxide which was added for the example shown here is large in comparison to concentrations usually observed at ambient conditions even in moderately or strongly polluted cities (Bari et al., 2003; Yang et al., 2009). Considering the large amount of $\mathrm{SO}_{2}$ added to the sample gas, a twofold increase in the background $\mathrm{H}_{2} \mathrm{SO}_{4}$ seems to be a negligible contribution and indeed, no crosssensitivity to $\mathrm{SO}_{2}$ is observed when only 20 ppbv are present in the sample gas which was tested in a separate experiment. This small contribution of $\mathrm{SO}_{2}$ to the signal is surprising as other groups have reported that an $\mathrm{OH}$ scavenger like propane (Berresheim et al., 2000) or $\mathrm{C}_{3} \mathrm{~F}_{6}$ (Dubey et al., 1996; Sjostedt et al., 2007) were used for similar instruments in order to reduce the background levels of $\mathrm{OH}$ or $\mathrm{H}_{2} \mathrm{SO}_{4}$ to an acceptable level. From our findings this seems not to be necessary for $\left[\mathrm{SO}_{2}\right]$ below $20 \mathrm{ppbv}$ (or even higher) when using CIMS for $\mathrm{H}_{2} \mathrm{SO}_{4}$ detection - even in conjunction with a corona ion source, a device normally known for producing higher background levels of unwanted substances in comparison to radioactive ion sources. The integration time for $\mathrm{m} / \mathrm{z}$ 64 and $m / z, 97$ were $0.25 \mathrm{~s}$ and $1 \mathrm{~s}$, respectively. One full cycle (which included acquiring data also for six additional $m / z$ values) was adjusted to $\sim 4.5 \mathrm{~s}$. An evaluation of the detection limit for the americium ion source yielded a value of $1 \times 10^{4} \mathrm{~cm}^{-3}$ when no $\mathrm{SO}_{2}$ was added to the sample gas and $2.8 \times 10^{4} \mathrm{~cm}^{-3}$ if $\mathrm{SO}_{2}$ was added at a similar concentration as for the experiment with the corona ion source, respectively. The count rate for $\mathrm{m} / \mathrm{z}, 64$ reached values up to $20000 \mathrm{~s}^{-1}$ for the americium source. The primary ion count rate of the corona ion source is therefore approximately 25 times lower. This effect should therefore lead to a factor $25^{0.5}=5$ lower detection limit while the actual detection limit is about a factor of 6.5 lower. This means that normalization by the primary ion count rate can explain the difference in the detection limits almost completely. The slight drift in the primary ion signal should therefore only lead to a small contribution. These drifts occur on the timescale of several hours and can reach maximum fluctuations of $\pm 50 \%$. It is also worth mentioning that the relative change in sensitivity due to the addition of $\mathrm{SO}_{2}$ is quite similar for both sources.

\section{Summary and Outlook}

The performance of a corona ion source for the detection of sulfuric acid by chemical ionization mass spectrometry has been evaluated. The corona ion source consists of a simple set-up and makes use of a commercially available goldplated acupuncture needle which can easily be installed and exchanged. 
The results show that this source yields the same quantitative results for a given $\mathrm{H}_{2} \mathrm{SO}_{4}$ concentration as compared to an americium ion source. The detection limit of the corona ion source is $\sim 6 \times 10^{4}$ molecule $\mathrm{cm}^{-3}$ of $\mathrm{H}_{2} \mathrm{SO}_{4}$ for one minute integration time in contrast to $\sim 1 \times 10^{4}$ molecule $\mathrm{cm}^{-3}$ for the americium source previously used. While the fluctuations of the primary ion signal are higher for the corona ion source than for the radioactive ion source, this higher noise translates only slightly into the determined $\mathrm{H}_{2} \mathrm{SO}_{4}$ concentration since the ratio between $\mathrm{HSO}_{4}^{-}$ions and $\mathrm{NO}_{3}^{-}$primary ions is stable. The corona ion source only shows a slight increase in background levels of $\mathrm{H}_{2} \mathrm{SO}_{4}$ when $\mathrm{SO}_{2}$ at a high concentration of $1 \mathrm{ppmv}$ is added to the sample gas and the detection limit then increases to $\sim 1.1 \times 10^{5} \mathrm{~cm}^{-3}$. For smaller concentrations (20 ppbv) of sulfur dioxide no contribution to $\mathrm{H}_{2} \mathrm{SO}_{4}$ was observed even without adding an $\mathrm{OH}$ scavenger into the sheath gas. Given these characteristics of the corona ion source, the more commonly used radioactive ion sources seem to have no substantial advantage over a corona-type ion source. This is especially the case when considering the strict safety regulations, the potential health risk and the higher costs which apply for the radioactive sources.

In future, we would like to improve the stability of the corona ion source and try to produce higher count rates for the primary ion. Making the insulating PEEK part smaller could minimize the accumulation of charges on the insulator surface and thereby decrease losses for ions. In addition, trying out different radial positions for the corona needle tip could lead to an increase in the signal, thereby improving the detection limits. Also the effect of a PID controller could be tested.

Acknowledgements. We thank Dave Tanner, Greg Huey and Bob Stickel from THS Instruments for helpful discussions and technical support. The research leading to these results has received funding from the EC's Seventh Framework Programme under grant agreement no. 215072 (Marie Curie Initial Training Network "CLOUD-ITN") and from the German Federal Ministry of Education and Research (project no. 01LK0902A “CLOUD-09").

Edited by: A. Hansel

\section{References}

Asbach, C., Kuhlbusch, T. A. J., and Fissan, H.: Effect of corona discharge on the gas composition of the sample flow in a Gas Particle Partitioner, J. Environ. Monit., 7, 877-882, 2005.

Bari, A., Ferraro, V., Wilson, L. R., Luttinger, D., and Husain, L.: Measurements of gaseous $\mathrm{HONO}, \mathrm{HNO}_{3}, \mathrm{SO}_{2}, \mathrm{HCl}, \mathrm{NH}_{3}$, particulate sulfate and PM2.5 in New York, NY, Atmos. Environ., 37, 2825-2835, 2003.

Berresheim, H., Elste, T., Plass-Dülmer, C., Eisele, F. L., and Tanner, D. J.: Chemical ionization mass spectrometer for long-term measurements of atmospheric $\mathrm{OH}$ and $\mathrm{H}_{2} \mathrm{SO}_{4}$, Int. J. Mass Spectrom., 202, 91-109, 2000.
Curtius, J.: Nucleation of atmospheric aerosol particles, C. R. Physique, 7, 1027-1045, 2006.

Dubey, M. K., Hanisco, T. F., Wennberg, P. O., and Anderson, J. G.: Monitoring potential photochemical interference in laserinduced fluorescence Measurements of atmospheric $\mathrm{OH}$, Geophys. Res. Lett., 23(22), 3215-3218, doi:10.1029/96GL03008, 1996.

Eisele, F. L. and Tanner, D. J.: Measurement of the gas phase concentration of $\mathrm{H}_{2} \mathrm{SO}_{4}$ and methane sulfonic acid and estimates of $\mathrm{H}_{2} \mathrm{SO}_{4}$ production and loss in the atmosphere, J. Geophys. Res., 98(D5), 9001-9010, 1993.

Fiedler, V., Dal Maso, M., Boy, M., Aufmhoff, H., Hoffmann, J., Schuck, T., Birmili, W., Hanke, M., Uecker, J., Arnold, F., and Kulmala, M.: The contribution of sulphuric acid to atmospheric particle formation and growth: a comparison between boundary layers in Northern and Central Europe, Atmos. Chem. Phys., 5, 1773-1785, doi:10.5194/acp-5-1773-2005, 2005.

Fortner, E. C, Zhao, J., and Zhang, R.: Development of Ion Drift-Chemical Ionization Mass Spectrometry, Anal. Chem., 76, 5436-5440, 2004.

Furutani, H. and Akimoto, H.: Development and characterization of a fast measurement system for gas-phase nitric acid with a chemical ionization mass spectrometer in the marine boundary layer, J. Geophys. Res., 107(D2), 4016, doi:10.1029/2000JD000269, 2002.

Jost, C., Sprung, D., Kenntner, T., and Reiner, T.: Atmospheric pressure chemical ionization mass spectrometry for the detection of tropospheric trace gases: the influence of clustering on sensitivity and precision, Int. J. Mass Spectrom., 223-224, 771-782, 2003.

Kuang, C., McMurry, P. H., McCormick, A. V., and Eisele, F. L.: Dependence of nucleation rates on sulfuric acid vapor concentration in diverse atmospheric locations, J. Geophys. Res., 113, D10209, doi:10.1029/2007JD009253, 2008.

Kukui, A., Ancellet, G., and Le Bras, G.: Chemical ionization mass spectrometer for measurements of $\mathrm{OH}$ and peroxy radical concentrations in moderately polluted atmospheres, J. Atmos. Chem., 61, 133-154, 2008.

Kulmala, M., Vehkamäki, H., Petäjä, T., Dal Maso, M., Lauri, A., Kerminen, V.-M., Birmili, W., and McMurry, P. H.: Formation and growth rates of ultrafine atmospheric particles: a review of observations, J. Aerosol Sci., 35, 143-176, 2004.

Kulmala, M. and Kerminen, V.-M.: On the formation and growth of atmospheric nanoparticles, Atmos. Res., 90, 132-150, 2008.

Sipilä, M., Berndt, T., Petäjä, T., Brus, D., Vanhanen, J., Stratmann, F., Patokoski, J., Mauldin III, R. L., Hyvärinen A.-P., Lihavainen, H., and Kulmala, M.: The Role of Sulfuric Acid in Atmospheric Nucleation, Science, 327, 1243-1246, 2010.

Sjostedt, S. J., Huey, L. G., Tanner, D. J., Peischl, J., Chen, G., Dibb, J. E., Lefer, B., Hutterli, M. A., Beyersdorf, A. J., Blake, N. J., Super, D., Ryerson, T., Burkhart, J., and Stohl, A.: Observations of hydroxyl and the sum of peroxy radicals at Summit, Greenland during summer 2003, Atmos. Environ., 41, 5122-5137, 2007.

Viggiano, A. A., Seeley, J. V., Mundis, P. L., Williamson, J. S. and Morris, R. A.: Rate constants for the reactions of $\mathrm{XO}_{3}^{-}\left(\mathrm{H}_{2} \mathrm{O}\right)_{n}$ $(\mathrm{X}=\mathrm{C}, \mathrm{HC}$, and $\mathrm{N})$ and $\mathrm{NO}_{3}^{-}\left(\mathrm{HNO}_{3}\right)_{n}$ with $\mathrm{H}_{2} \mathrm{SO}_{4}$ : implications for atmospheric detection of $\mathrm{H}_{2} \mathrm{SO}_{4}$, J. Chem. Phys. A, 101, 8275-8278, 1997.

Weber, R. J., McMurry, P. H., Eisele, F. L., and Tanner, D. J.: Mea- 
surement of expected nucleation precursor species and 3-500-nm diameter particles at Mauna-Loa-Observatory, Hawaii, J. Atmos. Sci., 52, 2242-2257, 1995.

Weber, R. J., Marti, J. J., McMurry, P. H., Eisele, F. L., Tanner, D. J., and Jefferson, A.: Measurements of new particle formation and ultrafine particle growth rates at a clean continental site, J. Geophys. Res., 102(D4), 4375-4385, 1997.

Weber, R. J., McMurry, P. H., Mauldin R. L., Tanner, D. J., Eisele, F. L., Clarke, A. D., and Kapustin, V. N.: New particle formation in the remote troposphere: A comparison of observations at various sites, Geophys. Res. Lett., 26, 307-310, 1999.

Yang, S., Yuesi, W., and Changchun, Z.: Measurement of the vertical profile of atmospheric $\mathrm{SO}_{2}$ during the heating period in Beijing on days of high air pollution, Atmos. Environ., 43, 468-472, 2009.
Young, L. H., Benson, D. R., Kameel, F. R., Pierce, J. R., Junninen, H., Kulmala, M., and Lee, S.-H.: Laboratory studies of $\mathrm{H}_{2} \mathrm{SO}_{4} / \mathrm{H}_{2} \mathrm{O}$ binary homogeneous nucleation from the $\mathrm{SO}_{2}+\mathrm{OH}$ reaction: evaluation of the experimental setup and preliminary results, Atmos. Chem. Phys., 8, 4997-5016, doi:10.5194/acp-84997-2008, 2008.

Yu, F. and Turco, R. P.: From molecular clusters to nanoparticles: The role of ambient ionization in tropospheric aerosol formation, J. Geophys. Res., 106(D5), 4797-4814, 2001.

Zheng, J., Zhang, R., Fortner, E. C., Volkamer, R. M., Molina, L., Aiken, A. C., Jimenez, J. L., Gaeggeler, K., Dommen, J., Dusanter, S., Stevens, P. S., and Tie, X.: Measurements of HNO3 and $\mathrm{N} 2 \mathrm{O} 5$ using ion drift-chemical ionization mass spectrometry during the MILAGRO/MCMA-2006 campaign, Atmos. Chem. Phys., 8, 6823-6838, doi:10.5194/acp-8-6823-2008, 2008. 